\title{
Social and visual function in nystagmus
}

\section{R F Pilling, J R Thompson, I Gottlob}

\begin{abstract}
Aim: To investigate the influence of nystagmus on visual and social function and determine if parents are able to assess visual and social function in children with nystagmus.

Method: A postal questionnaire comprising 14 questions related to visual function (VF-14) and questions pertaining to social function were sent to all 1013 members of the Nystagmus Network-a UK based organisation for nystagmus sufferers and their families. Visual and social function scores were compared by regression analysis.

Results: 180 adult, 233 parent, and 124 child questionnaires were returned. Idiopathic nystagmus was the most common cause. In adults the mean VF-14 score indicated very low visual function, in the same range as patients assessed in low vision services. Children's visual function scored better than adults, between scores of patients with age related macular disease and corneal grafts. There was a strong correlation between perceived visual and social function for adults $(p<0.001)$ and parental assessment of their children $(p<0.001)$, but not between child self assessment of visual and social function. There was strong correlation between parental and child assessment of visual and social function $(p<0.001, p<0.001)$

Conclusion: Questionnaires indicated that nystagmus is associated with very low visual function. There is a strong correlation between visual and social impairment. The authors have shown for the first time in an ophthalmic disease that parents are able to estimate the impact of nystagmus on their child both in terms of visual and social functioning, although they underestimate the impact of nystagmus on emotional aspects of wellbeing.
\end{abstract}

$\mathrm{N}$ ystagmus often occurs in early childhood and can be idiopathic, associated with albinism, ocular, or neurological diseases. The prevalence of infantile nystagmus is one in 1000-6000. ${ }^{12}$ The impact of nystagmus on visual function (VF; ability to perform activities of daily life) and social function (SF; self perception of wellbeing, interaction with and contribution to society) is unknown.

Functional impairment in ocular disease can be explored with questionnaires. The VF-14 is a valid, reliable tool for measuring visual impairment. It was designed for patients with cataract ${ }^{3}$ and has been used for other visual diseases. ${ }^{4-8}$ $\mathrm{VF}$ is variably affected depending on the eye disease. Experienced difficulties have found to be contrast and near tasks in cataract, ${ }^{3}$ sport in myopia, ${ }^{4}$ and fine details and driving in macular degeneration. ${ }^{5}$

Disease specific tools ${ }^{3-13}$ have been developed. These questionnaires contain items of little relevance for patients with nystagmus who have, in addition to visual impairment from unusual eye movements, abnormal head movements and/or oscillopsia. Factors associated with quality of life in visual impairment include worry, independence, concerns about the future, social relationships, and career. ${ }^{912}{ }^{13}$
Because of altered cosmesis, teasing and self confidence was found to be changed in myopia, ${ }^{4}$ while abnormal head posture and ocular deviation affected interpersonal communication and employment in strabismus. ${ }^{12}$

Poor VF is associated with poor $\mathrm{SF}^{89^{11-13}}$; however, the psychosocial implications of the effect of nystagmus has not, to our knowledge, been investigated. Our aim was to quantify and compare VF and SF in nystagmus including a comparison of parental and child perception.

\section{METHODS}

Questionnaires were sent anonymously to all (1013) members of the Nystagmus Network UK (NN), a charity for patients and families with nystagmus. Envelopes contained three questionnaires - one for affected adults, one for parents of affected children, and one for affected children. Upon request, additional questionnaires (for example, more than one child affected) and questionnaires on disc and tape were supplied. A reminder was placed in the NN newsletter after 2 months. Questionnaires returned after 6 months were included.

The original VF-14 was used to assess VF ${ }^{3}$ (see appendix). The question pertaining to driving was omitted for children. A SF questionnaire was derived from vision and social function related questionnaires ${ }^{914}$ for adults and children with nystagmus. Parents were asked to respond about their child and consider if their child could independently complete an additional questionnaire. Returned parent and child responses were directly compared using VF-14 and SF questions appearing in the same form on both questionnaires (see appendix). There were variations between parental and child questionnaires, to incorporate preschool child assessment (see appendix). Additional questions addressed sex, age, and nystagmus type.

Following a pilot questionnaire sent to NN committee members, the number of questions for children was reduced (questions 15-17 removed), wording was altered to aid comprehension (question 11; "Do you feel lonely" to "Do you feel isolated"), and several social score questions were changed to a positive turn (adult A, B, C, L: parent 15-17).

SF questions were given scores between $\mathrm{l}$ and $4(\mathrm{l}=$ great deal of difficulty, $2=$ moderate difficulty, $3=$ a little bit of difficulty, $4=$ no difficulty). ${ }^{3}$ Questions 1,2 , and 12 had scores reversed to account for their positive turn. Scores were divided by number of questions answered, then multiplied by 25 to give total scores in the range 0-100: the higher the score, the better the function. Results were compared using regression analysis on SPSS.

\section{RESULTS}

In all, $398(39 \%)$ of the 1013 envelopes were returned, containing 180 adult and 233 parent/child questionnaires; 22 with more than one affected family member.

Abbreviations: NN, Nystagmus Network; SF, social function; VF, visual function 
Table 1 Aetiologies, mean VF-14 score, and social score for adult, parental assessment of child and child self assessment

\begin{tabular}{|c|c|c|c|c|c|c|c|c|c|c|}
\hline \multirow[b]{2}{*}{ Aetiology } & \multirow{2}{*}{$\begin{array}{l}\text { Adult } \\
(n=180)\end{array}$} & \multirow{2}{*}{$\begin{array}{l}\text { Adult } \\
\%\end{array}$} & \multirow{2}{*}{$\begin{array}{l}\text { Child } \\
(n=233)\end{array}$} & \multirow{2}{*}{$\begin{array}{l}\text { Child } \\
(\%)\end{array}$} & \multicolumn{3}{|l|}{ VF-14 } & \multicolumn{3}{|c|}{ Social score } \\
\hline & & & & & Adult & Parent & Child & Adult & Parent & Child \\
\hline Albinism & 25 & 14 & 44 & 19 & 55 & 65 & 48 & 53 & 80 & 78 \\
\hline Bad eyesight & 9 & 5 & 5 & 2 & 44 & 53 & 50 & 47 & 87 & 64 \\
\hline Neurological & 19 & 10 & 12 & 5 & 46 & 51 & 33 & 46 & 67 & 78 \\
\hline Pregnancy/birth & 9 & 5 & 4 & 2 & 55 & 74 & & 55 & 78 & 68 \\
\hline Squint & 4 & 2 & 5 & 2 & 58 & 81 & 83 & 67 & 76 & 83 \\
\hline Not sure & 41 & 23 & 21 & 9 & 56 & 77 & 67 & 53 & 83 & 83 \\
\hline Idiopathic/no reason & 61 & 34 & 95 & 41 & 65 & 73 & 77 & 59 & 82 & 83 \\
\hline Missing data & 12 & 7 & 48 & 21 & & & & & & \\
\hline Mean & & & & & 55 & 73 & 69 & 76 & 71 & 66 \\
\hline SD & & & & & 23 & 25 & 24 & 13 & 16 & 27 \\
\hline Range & & & & & $0-100$ & $15-100$ & $6-100$ & $32-94$ & $35-95$ & $25-100$ \\
\hline
\end{tabular}

\section{Adult data}

The mean age of adult responders was 41 years (range 18-75, SD 15.6; $52 \%$ females and $48 \%$ males). The most common nystagmus cause was idiopathic/no reason (table 1 ).

Figure lA shows the correlation between VF-14 and SF scores for adults $\left(R^{2}=0.35, p<0.001\right)$. There was a trend for higher VF-14 scores in idiopathic nystagmus than for other aetiologies. Neither SF nor VF was associated with age or sex.

\section{Parent and child data}

Of the 233 datasets, 124 contained a non-affected parent together with an affected child response. The average age of affected children was 7.5 years (range $0-18$, SD 4.3). The male:female ratio was 60:40. The most common nystagmus cause was idiopathic/no reason (table 1). A trend was found for higher parental than child self assessment of VF and higher VF-14 scores in both parental and child self assessment for idiopathic nystagmus than other aetiologies. In contrast with adults, nystagmus associated with squint had a high VF. A weak positive association was found between VF and age $(\mathrm{p}<0.044)$. No association was found between sex and VF-14 score.
Table 2 Comparison of VF 14 scores from this study with other chronic ocular diseases

\begin{tabular}{lll}
\hline Aetiology & VF & Ref \\
\hline Low vision & $54-62$ & 8 \\
Adult nystagmus & 55 & \\
Age related macular degeneration & 62 & 5 \\
Child nystagmus (self) & 69 & \\
Precorneal graft & $72-76$ & 6 \\
Child nystagmus (parent) & 73 & \\
Retinal disease & 84 & 7 \\
Myopia & 91 & 4 \\
\hline
\end{tabular}

There was strong positive correlation between parental assessment of child VF and SF $\left(\mathrm{R}^{2}=0.39, \mathrm{p}<0.001\right)$ (fig 1B). Figure $\mathrm{IC}$ and $\mathrm{D}$ show correlations between SF scores $\left(\mathrm{R}^{2}=0.72, \mathrm{p}<0.001\right)$ and VF-14 scores $\left(\mathrm{R}^{2}=0.74\right.$, $\mathrm{p}<0.001$ ) assessed by children and parents. A positive association was found with age for SF scores for parental and child assessment, but not for sex or type of nystagmus.
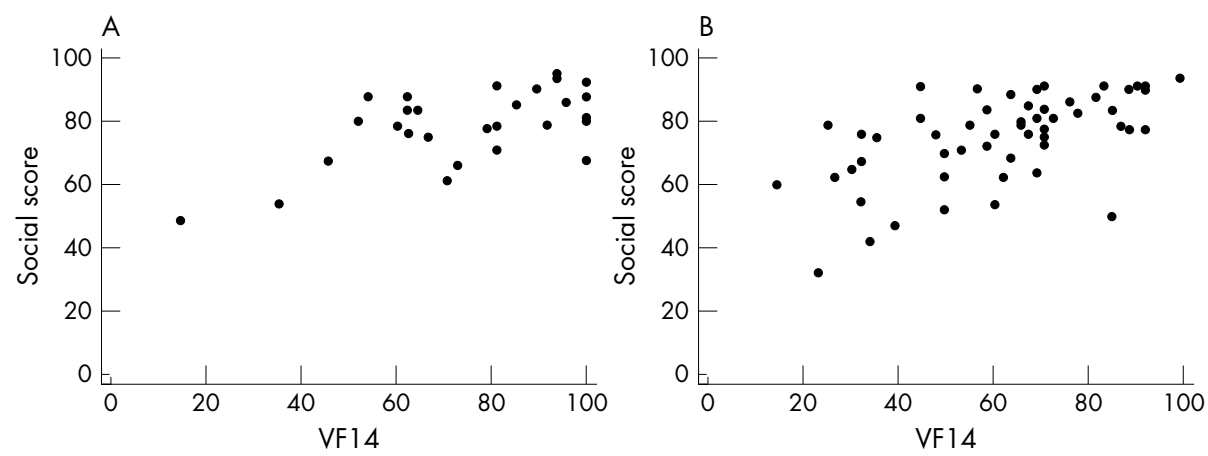

Figure 1 (A) Adult VF-14 score versus social function score. (B) Parent

assessment of child VF-14 versus social function score. (C) Parent versus child self assessment of social function score. (D) Parent versus child self assessment of VF-14.
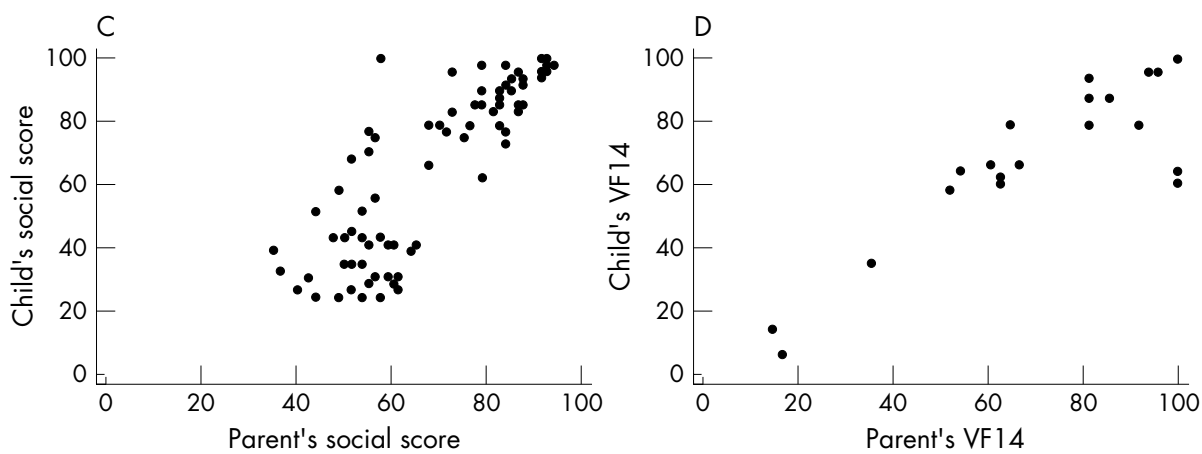
Although parents' and children's assessment of social score correlated highly, there was disagreement on two questions: $11 \%$ of parents thought their child was bullied "a great deal" because of nystagmus, whereas $26 \%$ children with nystagmus responded this way; $3 \%$ of parents thought their child worried a great deal about eyesight but $32 \%$ children responded likewise.

VF-14 was higher in children than adults. Adults thought they had a great deal of difficulty recognising people (11\%); this was a problem for only a few children $(2 \%)$ or their parents $(4 \%)$. Twenty seven per cent of adults reported inability to participate in sports, in contrast with $3 \%$ of children.

\section{DISCUSSION}

We found a strong correlation between VF and SF for adults and parental assessment of children with nystagmus and between parental and child self assessment of VF and SF.

Children had lower SF scores than adults. Most children scored low in areas concerned with appearance and confidence, whereas few adults thought that career and education had been affected by nystagmus. This may reflect difficulty in accepting those who are "different" by children. Children's lifestyles affect their current wellbeing, development, and adult health. ${ }^{12}{ }^{13} 16$ Studies on quality of life with strabismus and amblyopia show interference with schooling, influence in job choice, and social activity. ${ }^{12}{ }^{13}$ Research on childhood strabismus concluded that psychological development and self esteem suffered because of other children's attitudes. ${ }^{12}$

An association was found with age for parental assessment of child VF and SF. Decreasing nystagmus amplitude with age $^{17}$ might contribute to better VF and SF scores in older children. However, measuring VF and SF is challenging in children because of difficulties in interpreting social interaction, varying parental experience, and rapid change in skills. ${ }^{18}$

The visual impairment caused by nystagmus is shown in table $2{ }^{4-8}$ For adults it is equivalent to patients requiring low vision aids. In children it is above VF in patients with age related macular degeneration.

A lower mean VF score was found for albinism than for idiopathic nystagmus. Patients with idiopathic nystagmus have better visual acuity than in secondary nystagmus. ${ }^{1}$ In future studies it would be interesting to correlate visual acuity with VF and SF.

It is possible nystagmus sufferers who are members of NN are biased towards worse VF. A response rate of 39\% may reflect those with worse vision. However, VF ranged widely (0-100 adults: $6.25-100$ children), enabling us to correlate a wide range of VF with SF.

In our study parents and children showed agreement between SF and VF. To our knowledge no previous studies compared parental assessment and child self assessment of VF. Current research regarding chronic childhood disease ${ }^{19-21}$ shows parents overestimate the illness impact on physical ability, but underestimate emotional, cognitive, and social implications. This is confirmed here, where parents overestimated difficulty with participating in sports and underestimated the impact of appearance and the likelihood of being bullied because of nystagmus. Children indicating fewer problems with sports than adults could reflect on good school integration, the competitive nature of organised sport for adults, or other neurological impairment in adults with acquired nystagmus.

It is possible that children completing self assessment questionnaires were influenced by parents. However, consistent differences in results (for example, bullying and appearance) support independent completion of questionnaires.
The majority of ocular quality of life questionnaires concentrate on tasks and symptoms rather than wellbeing and SF. It is important to develop quality of life instruments, which correlate visual acuity with functional ability and integration in society, to judge the impact of visual disability and appropriately direct services.

\section{CONCLUSION}

Poor VF is associated with poor SF in nystagmus. This is the first study to show VF scores in nystagmus are low compared with other causes of chronic visual loss. We show for the first time in an ophthalmic disease that parents are able to estimate the impact of nystagmus on visual and social functioning, and are well placed to assess their child's needs. Children with nystagmus perceive social exclusion, which should be addressed by a multidisciplinary team.

\section{ACKNOWLEDGEMENTS}

We thank the members of the Nystagmus Network for help designing and piloting the questionnaires and members of the Nystagmus Network who participated. This study was supported by the Ulverscroft Foundation.

\section{Authors' affiliations}

R F Pilling, Department of Ophthalmology, University Hospitals Leicester, Infirmary Square, Leicester LE1 5WW, UK

J R Thompson, Department of Health Sciences, University of Leicester, 22-28 Princess Road West, Leicester LE1 6TP, UK

I Gottlob, Department of Ophthalmology, University of Leicester, Robert Kilpatrick Clinical Sciences Building, Leicester Royal Infirmary, PO Box 65, Leicester LE2 7LX, UK

Competing interests: none declared

Correspondence to: Professor Irene Gottlob, Department of Ophthalmology, Robert Kilpatrick Clinical Sciences Building, Leicester Royal Infirmary, PO Box 65, Leicester LE2 7LX, UK; ig15@le.ac.uk

Accepted for publication 25 May 2005

\section{APPENDIX}

\section{VISUAL FUNCTION- 14}

\section{Do you have any difficulty, even with glasses.....}

l Reading small print-eg, food label, phone book

2 Reading a book or newspaper

3 Reading a large print book or recognising numbers on TV

4 Recognising people when they are close to you

5 Seeing steps, stairs, or curbs

6 Reading traffic signs, street signs, or shop signs

7 Doing fine handwork-eg, sewing, knitting, crafts

8 Filling in forms

9 Playing games—eg, cards, dominoes, board games

10 Taking part in sport

11 Cooking

12 Watching television

13 Driving during the day-omitted from child questionnaire

14 Driving at night_omitted from child questionnaire

\section{ADULT SOCIAL SCORE (*SCORES REVERSED) \\ Because of nystagmus}

A Do you enjoy making friends?*

B Do you go out socially?*

C Do you consider yourself independent?*

E Were decisions about further education affected?

F Were decisions about career choice affected?

$\mathrm{G}$ Has career progression been affected?

H Do you feel you have been prevented from working?

I Do you worry about losing your job?

J Do you dislike leaving home on your own?

$\mathrm{K}$ Do you have problems getting along with people? 
L Do you have difficulty caring for family members? M Are you happy with life?*

$\mathrm{N}$ Do you need help from other people?

O Do you feel less inclined to meet new people?

$\mathrm{P}$ Do you feel less inclined to meet family?

Q Do you feel isolated from those around you?

$\mathrm{R}$ Do you feel frustrated with life?

S Have you been bullied or teased?

T Do you worry about your eyesight?

U Are you concerned about your appearance?

\section{CHILD SOCIAL SCORE - SELF ASSESSMENT}

(Underlined questions used for direct comparison)

1 Are you shy, withdrawn, or nervous?

2 Do you spend time worrying about your vision?

3 Do you feel frustrated?

4 Have you been bullied or teased?

5 Are you concerned about your appearance?

6 Do you have difficulty making friends?

7 Do you need help at school?

8 Do you consider yourself disabled or handicapped?

9 Do you feel less inclined to go out and meet friends?

10 Do you feel less inclined to meet family?

11 Do you feel lonely?

\section{CHILD SOCIAL SCORE - PARENTAL ASSESSMENT Because of nystagmus....}

I Is he/she shy withdrawn or nervous?

2 Does he/she spend time worrying about their vision?

3 Is he/she frustrated?

4 Has he/she been bullied or teased?

5 Is he/she concerned about his/her appearance?

6 Does he/she have difficulty making friends?

7 Does he/she need help at school?

8 Do you consider your child disabled or handicapped?

9 Do you feel less inclined to meet new friends?

10 Do you feel less inclined to meet family?

11 Do you feel isolated from other parents?

12 Do you feel downhearted?

13 Do you worry about future children having nystagmus?

14 Are you concerned about your child's appearance?

15 Is your child happy?*
16 Does your child get on well at school?*

17 Does your child interact well with other children?*

\section{REFERENCES}

1 Abadi RV, Bjerre A. Motor and sensory characteristics of infantile nystagmus. Br J Ophthalmol 2002;86:1152-60.

2 Hemmes GD. Hereditary nystagmus. Am J Ophthalmol 1924;10:149-50.

3 Steinberg EP, Tielsen JM, Schien OD, et al. The VF14-an index of functional impairment in patients with cataract. Arch Ophthalmol 1994;1 12:630-638.

4 Ross K, Harper R, Tromans C, et al. Quality of life in myopia. Br J Ophthalmol 2000;84:1031-4

5 Riusala A, Sarna S, Immonen I. Visual function 14 in long duration age related macular degeneration Am J Ophthalmol 2003;135:206-12.

6 Boisjoly H, Grosset J, Fontaine N, et al. The VF14 index of functional visual improvement in candidates for corneal graft. Am J Ophthalmol 1999; 128:38-44.

7 Linder M, Chang TS, Scott IU, et al. Validity of VF14 in patients with retinal disease. Arch Ophthalmol 1999;117:1611-16.

8 Scott IU, Smeddy WE, Schiffman J, et al. Quality of life of low vision patients and the impact of low vision services. Am J Ophthalmol 1999;128:54-6231.

9 Mangione CM, Berry S, Spritzer MS, et al. Identifying content area for the 51 item NEI-VFQ. Arch Ophthalmol 1998;1 16:227-33.

10 Mangione CM, Phillips RS, Seddon JM, et al. Development of the Activities of Daily Vision Scale'. Med Care 1992;30:1111-26.

11 Terwee CB, Gerding MN, Dekeer FW, et al. Development of a disease specific quality of life questionnaire for patients with Graves' ophthalmopathy: the GO-QOL. Br J Ophthalmol 1998;82:773-9.

12 Sutterfield D, Keitner JL, Morrison TL. Psychosocial aspects of strabismus study. Arch Ophthalmol 1993;111:1100-5.

13 Packwood EA, Cruz O, Rychwalski PJ, et al. The psychosocial effects of amblyopia study. J AAPOS 1999;3:15-17.

14 Jette AM, Davies AR, Cleary PD, et al. The functional status questionnaire: reliability and validity when used in primary care. J Gen Int Med 1986;1:143-9.

15 Eiser C, Morse R. Can parents rate their child's health-related quality of life? Results of a systematic review. Qual Life Res 2001;10:347-57.

16 Antwerp CA. The lifestyle questionnaire for school aged children: a tool for primary care. J Paediatr Health Care 1995;9:251-5.

17 Reinecke RD, Guo S, Goldstein HP. Waveform evolution in infantile nystagmus: an electro-oculo-graphic study of 35 cases. Binoc Vis 1988;3:191-202.

18 Felius J, Stager DR, Berry PM, et al. Development of an instrument to assess vision-related quality of life in young children. Am J Ophthalmol 2004; 138:362-72.

19 Erickson SR, Munzenberger PJ, Plante MJ, et al. Influence of sociodemographics on the health-related quality of life of pediatric patients with asthma and their caregivers. J Asthma 2002;39:107-17.

20 Ennett ST, DeVellis BM, Earp JA, et al. Disease experience and psychosocial adjustment in children with juvenile rheumatoid arthritis: children's versus mothers' reports. J Paediatr Psychol 1991;16:557-68.

21 Theunissen NC, Vogels TG, Koopman HM, et al. The proxy problem: child report versus parent report in health-related quality of life research. Qual Life Res 1998;7:387-97. 